Running head: POLITICAL CORRELATES OF LISTENING STYLES

Political Correlates of Apophatic and Cataphatic Listening Styles

Eike Mark Rinke

University of Mannheim

Patricia Moy

University of Washington

August 13, 2018

Paper to be presented at the annual meeting of the American Political Science Association, Boston, MA.

The data and code required to reproduce all analyses in this paper are available from the authors upon request. We thank Maria Len-Rios for her collaboration in the survey design and implementation. Address correspondence to Eike Mark Rinke, Mannheim Centre for European Social Research (MZES), University of Mannheim, 68131 Mannheim, Germany. E-mail: rinke@uni-mannheim.de. 


\begin{abstract}
While it is a truism that political voice is a cornerstone of democratic theory, less theorizing has focused on its counterpart, political listening. Drawing upon research related to listening practices, this study operationalizes for empirical study Dobson's (2014) normative concepts of apophatic listening, which is dialogic and facilitates discussion across lines of difference, and cataphatic listening, which is monologic and disruptive in nature. Using data from a national sample survey of Latinos fielded shortly after the 2016 U.S. presidential election $(N=720)$, we provide an empirical test of these listening practices' democratic value by examining how relational and analytical listening (dimensions of apophatic practices) and task-oriented and critical listening (dimensions of cataphatic practices) are associated with various political outcomes, including political interest, knowledge, trust, and participation. Findings indicate that, from a normative point of view, task-oriented listening was unrelated or negatively related to political outcomes while relational listening had ambivalent relations. However, the two cognitive-epistemic dimensions of both types of listening - analytical listening and critical (error-seeking) listening - were both strongly and positively related to most studied political outcomes. These findings offer nuanced evidence that apophatic and cataphatic listening might not necessarily be at odds with each other where democratically desirable outcomes are concerned.
\end{abstract}




\section{Political Correlates of Apophatic and Cataphatic Listening Styles}

While democratic theorists have posed questions of "democratic listening" for quite some time (e.g., Bickford, 1996), the lion's share of normative democratic theory and empirical political communication research has focused on matters of political "voice." However, a growing body of literature recently has foregrounded questions of political listening in normative discussions about democratic life. In the view of democratic theorists (e.g., Dobson, 2012, 2014; Ercan, Hendriks, \& Dryzek, in press; Scudder, 2016) and political sociologists (e.g., Bassel, 2017; Couldry, 2009), citizens' "democratic-listening" practices, especially across lines of political difference, are increasingly vital to the functioning of democracy and can be equally important as its counterpart "democratic voice." In political contexts especially, the inclusion of marginal groups requires communication across lines of social difference. For such precarious communication to be successful, members of all involved groups need to be not only heard, but also listened to.

Unfortunately, this increased normative interest in democratic listening has not yet been matched by corresponding efforts at understanding the antecedents, processes, and consequences of citizens' interpersonal listening practices for specific political outcomes and democratic life in general. If such efforts were undertaken, they have taken the form of qualitative case studies of political-listening processes and interventions aimed at the empowerment of marginal communities (e.g., Harcup, 2015; Thill, 2009; Waller, Dreher, \& McCallum, 2015). In this paper, we distinguish productive from unproductive forms of listening at the level of individual communicators, drawing on the normative conceptualization of listening practices introduced by Andrew Dobson (2014). By bringing his distinction between apophatic ("good") and cataphatic ("bad") political listening to existing literatures in empirical listening research, we employ, for the first time, a reliable and valid instrument that allows us to study apophatic and cataphatic 
listening styles on an individual level in a large-scale general population survey. Drawing on data from a representative survey of Latinos following the 2016 U.S. presidential election, we provide the first available exploration of cognitive, attitudinal, and behavioral political correlates of different listening styles.

\section{Capturing Two Types of Democratic Listening}

Several normative theories of democracy have emphasized the importance of listening (on the part of citizens and politicians alike) that supports various desirable democratic outcomes like understanding, recognition, and even reconciliation between deeply divided groups in society (e.g., Bickford, 1996; Ercan et al., in press; Scudder, 2016). One of the most developed and widely discussed normative concepts of political listening has been proposed by Dobson (2014, pp. 65-72), who broadly characterizes productive forms of listening as apophatic listening and unproductive forms of listening as cataphatic listening.

Apophatic listening, in Dobson's conceptualization, involves listeners putting their own schema into temporary suspension in order to "hear out" a speaking other without disrupting that person internally, for example, by thinking of counterarguments to what is being uttered. In this way, apophatic listening is dialogic and facilitates productive, structured negotiation of political disagreement in communication across lines of difference. In contrast, cataphatic listening involves listeners imposing their own preexisting schema onto what is being said by a speaking other, potentially disrupting the transmission of meaning. In this sense, cataphatic listening is monologic and disruptive, and may hamper the emergence of true understanding between interlocutors who do not share the same set of schema, considerations, and interests.

While Dobson's conceptualization provides an important normative vantage point from which to study democratic communication, especially across lines of political difference, we have not in the past had any measure to do so empirically. We therefore draw on an entirely 
different body of work, the empirical listening-studies literature, and map Dobson's normative listening concepts onto the dimensions of listening captured by the Listening Styles Profile-Revised (LSP-R), a revised version of the most widely used self-report listening instrument in the communication discipline introduced by Bodie, Worthington, and Gearhart (2013). The LSP-R measures the generalized, trait-like listening dispositions of individuals in four dimensions: relational, analytical, task-oriented, and critical listening (Bodie et al., 2013; see also Watson, Barker, \& Weaver, 1995).

We propose that the social-moral dimension of apophatic listening corresponds to relational listening, which is the tendency of a listener to be empathetic and listen out for the emotions of the speaker, while its epistemic-cognitive dimension corresponds to analytical listening, in which a listener attempts to understand and process all communicated information before forming an opinion. The social-moral dimension of cataphatic listening, on the other hand, corresponds to the LSP-R dimensions of task-oriented listening, a tendency of listeners to reduce listening to the transmission and reception of information relevant to solving a problem at hand, while its epistemic-cognitive dimension corresponds to critical listening, which is a tendency of a listener to search for errors in what others are saying (see Figure 1).

[Figure 1 about here]

By proposing an empirical operationalization of apophatic and cataphatic listening, our study aims to empirically test the assumptions enshrined in Dobson's normative theory of political listening. In other words, this study provides an empirical validation of his particular listening-centric theory of democracy and his assumptions about the beneficial nature of apophatic listening and the deleterious nature of cataphatic listening. In sum, we draw upon existing literature in empirical-listening research to offer an approach that allows us to study, at 
the level of individual communicators, those productive and unproductive forms of listening as conceived by Dobson.

\section{Political Correlates}

Our interest in the political correlates of listening styles stems from longstanding theorizing about what constitutes an ideal citizen. While few scholars would argue that citizens should be politically knowledgeable and active (see Dahl, 1989), greater variance exists in studies of political knowledge and political behavior. Indeed, given today's complex media landscape, scholars have focused on, for instance, how acts of online vs. offline political participation differ (e.g., Oser, Hooghe, \& Marien, 2013) or the normative implications of various dimensions of political knowledge (Ivie \& St. Onge, 2016). Our goal in this paper is not to settle ongoing debates, but to provide a first examination of how apophatic and cataphatic listening styles may relate to citizens' engagement with their social and political world. As Delli Carpini (2004, p. 396) summarized, the engaged citizen generally adheres to democratic norms and values, holds informed and empirically grounded opinions and beliefs, and works to enhance the quality of public life. 


\section{Political Cognitive Motivations}

To the extent that variations exist across domains of political engagement, political interest plays a critical role in shaping what citizens know and how they behave. Politically interested individuals, by virtue of having attained higher levels of education, tend to possess the ability and schemas that allow them to process information (Nie, Junn, \& Stehlik-Barry, 1996); as well, these individuals are more motivated to attend to political information (Xenos \& Moy, 2007). Indeed, Norris (2003) contends that political interest, not education, is key to determining political engagement. And while levels of political interest might be relatively stable, high-profile events and pressing societal problems and the media coverage they generate can produce even higher levels of interest (Schudson, 1998; Zaller, 2003).

Similarly, individuals' preexisting orientations regarding political information - for instance, their needs or motivations for turning to news coverage of an issue - shape the extent to which they can learn from the information they encounter. Decades of research on uses and gratifications have shown that someone who turns to the media for surveillance purposes will learn more from the media than someone not motivated to learn about their environment (Rubin, 2002).

We thus expect that political interest and motivations to learn about politics to be more strongly related with listening styles that emphasize the intake of political information - i.e., analytical listening and critical listening.

\section{Political Information Processing}

The strategies individuals employ to cope with the increasing onslaught of information also shape the extent to which they learn about politics. However, processing of that information requires first and foremost attention to that information, or focused mental effort on that content (Eveland, 2001). 
The information-processing strategies that individuals use have great implications for their knowledge of and engagement with the world around them (McLeod, Kosicki, \& McLeod, 2002). Less demanding processing strategies include selective scanning, in which one skims through content and tunes out some stories or content. More effortful strategies include active processing, in which one goes beyond a story to "read through" it and interpret it according to his/her own needs, and reflective integration, which involves drawing on multiple sources of information about a given topic and processing that information in tandem. Of interest to this study are the more effortful strategies that require cognitive elaboration. We expect that elaborative processing of information to be positively associated with apophatic (or "good") listening, often characterized by listening across lines of difference and "hearing out" and understanding another person's perspective. Similarly, elaborative processing should be negatively correlated with cataphatic (or "bad") listening, which reflects an individual's tendency to impose his/her own schemata on a conversation, at the expense of understanding others' views.

\section{Factual Political Knowledge}

Closely tied to cognitive orientations and information-processing strategies, individuals' knowledge of politics is heralded as a cornerstone to democratic citizenship. If an electorate is informed, its citizens are able to hold policy preferences that reflect their self-interests - and to protect those interests. However, scholars have long debated what constitutes knowledge or information. Early conceptualizations argued that "[the democratic citizen] is supposed to know what the issues are, what their history is, what the relevant facts are, what alternatives are

proposed, what the party stands for, what the likely consequences are" (Berelson, Lazarsfeld, \& McPhee, 1954, p. 308), and that citizens need to know what government is and does (Barber, 1973) as well as specific information about their leaders (Delli Carpini \& Keeter, 1996). What 
Americans should know then include: "the rules of the game, the substance of politics, and people and parties" (Delli Carpini \& Keeter, 1996, p. 65).

Attending to the political information environment naturally enhances the probability of individuals learning about politics. However, citizens' levels of political knowledge likely are a function of information gleaned from both mediated communication and interpersonal discussion. Empirical evidence bears this out: Media effects on political learning are greater among individuals who also have engaged in discussion (Scheufele, 2002). This

differential-gains hypothesis suggests that interpersonal discussion and, by extension, apophatic listening should be positively related to factual political knowledge.

\section{Political Attitudes}

If citizens adhere to democratic norms and values, they should better understand the significance of disagreement and its implications for policy and society. Greater normative value placed on political disagreement therefore should be positively related to apophatic listening and negatively with cataphatic listening. In other words, when individuals engage in more relational and analytical listening, their acceptance of disagreement should be greater. Conversely, when citizens are not mindful of others, their communication styles, or their views, they should more opposed and less understanding of what political disagreement means to democracy.

Similarly, we would expect the reverse relationships to emerge between listening styles and social dominance orientation (SDO), the preference for inequality among social groups (Pratto, Sidanius, Stallworth, \& Malle, 1994). Because high-SDO individuals tend to be less empathetic, tolerant, communal, or altruistic (Pratto et al., 1994), and more likely to be sexist, believe in hierarchy-enhancing ideologies (Pratto, Sidanius, \& Levin, 2006), it stands to reason that they also engage more in cataphatic listening. Low-SDO individuals endorse equality-related values and practices and therefore should be more likely to engage in apophatic listening. 
Also as a political attitude, we are interested in how political trust relates to listening styles. What citizens learn about elected officials and democratic institutions very likely derives from mediated information and can serve as fodder for political discussion. If the differential-gains hypothesis holds (Scheufele, 2002), the interactive effect of mediated and interpersonal communication will generate greater knowledge about these institutions, and knowledge has been linked empirically to greater political trust (Moy \& Pfau, 2000). Therefore, we expect apophatic listening to be positively related to political trust.

\section{Political Participation}

Finally, to the extent that citizens' activities affect politics, the myriad opportunities to engage in acts of political participation have only exponentiated with the proliferation of the internet, social media, and other information technologies. Categorized into numerous typologies (e.g., online vs. offline, civic vs. political, vertical vs. horizontal, traditional vs. nontraditional), the minimalist definition of political participation requires that the act be a behavior undertaken voluntarily by citizens in the political, state, or governmental sphere (van Deth, 2014).

To this end, we are interested especially in how listening styles relate to individual (solitary) acts of participation vs. collective, socially oriented acts of participation. If solitary acts of political participation require only the citizen and no political allies (e.g., emailing a politician or bearing a political button), then those engaging in such behaviors might be less sensitive to those around them and therefore might be lower in apophatic listening. That is, they might be less concerned with how others feel and be less likely to listen to what others have to say before forming judgments.

Conversely, individuals with a tendency to engage in acts of political participation that inherently require the presence of others (e.g., attending a town-hall meeting) might very well be predispositioned to be more relational and analytical. In other words, anticipating the presence of 
others and possibly needing to communicate and be most effective in communicating their views would require them to be more relational and analytical (apophatic) in their listening.

\section{Methods}

To empirically examine the political correlates of listening styles, we included key measures in an online Qualtrics consumer panel fielded December 7-17, 2016. The panel comprised adults of Hispanic or Latino/a ethnicity who lived in the United States and/or its territories and voted in the 2016 U.S. presidential election. In addition, quotas were set to recruit an equal number of male and female participants as well as a variety of Latino ethnicities. A total of $N=720$ participated in the survey, with $M_{\mathrm{age}}=33.7$ years $(\mathrm{SD}=12.8)$ and just over half $(50.3 \%)$ female. Respondents' averaged just over three decades' residence in the U.S. $(\mathrm{M}=31.0$, $\mathrm{SD}=13.0$ ) and were diverse in educational background (less than high school: $2.8 \%$; high-school graduate/GED: 19.3\%; some college: 30.8\%; two-year college degree: $14.6 \%$; four-year college degree: 23.3\%; Master's degree: 6.8\%; doctoral or professional degree (e.g., JD, MD): $2.4 \%$ ) . Within the sample, $66.5 \%$ identified as Mexican American, $11 \%$ as Puerto Rican, 7\% as Cuban American, 3\% as multiethnic Hispanic, and 2.1\% Dominican; the rest were divided among other Central, South American, and Spanish ethnicities.

\section{Key Variables of Interest: Listening Styles}

In order to measure apophatic and cataphatic listening in line with the approach described above (see Figure 1), we draw on a newly developed and validated short form of the established LSP-R, the Listening Styles Profile-Revised short scale (LSP-R8), which measures the four empirical dimensions of listening with just eight items (Rinke, 2016; see also Bodie \& Worthington, 2017). Unlike its predecessors, this newly validated short form allows for the self-report measurement of listening in general-population surveys. To our knowledge, this study 
is the first ever to have implemented a validated measure of interpersonal listening styles in a national-level survey.

The LSP-R8 consists of a battery of eight seven-point Likert items that tap into four dimensions of individuals' listening styles ( 1 = "strongly disagree"; 7 = "strongly agree"). Relational listening, which emphasizes empathy and concern for others' feelings, emotions, and moods, was assessed by two items: "When listening to others, I am mainly concerned with how they are feeling" and "I listen to understand the emotions and mood of the speaker" $(\mathrm{M}=5.02$, $\mathrm{SD}=1.22$; Cronbach's alpha $=.65)$. Analytical listening, reflected in one's waiting to secure additional information before reaching a conclusion, was tapped by two items, "I wait until all the facts are presented before forming judgments and opinions" and "I fully listen to what a person has to say before forming any opinions" $(\mathrm{M}=5.52, \mathrm{SD}=1.20$; Cronbach's alpha $=.77)$. To measure task-oriented listening, the survey asked respondents their level of agreement or disagreement with two items (reverse-coded): "I am impatient with people who ramble on during conversations" and "I find it difficult to listen to people who take too long to get their ideas across" $(\mathrm{M}=4.84, \mathrm{SD}=1.44 ;$ Cronbach's alpha $=.72)$. Finally, two items tapped into critical thinking: "I often catch errors in other speakers' logic" and "I tend to naturally notice errors in what other speakers' say" $(\mathrm{M}=5.22, \mathrm{SD}=1.20$; Cronbach's alpha $=.77)$.

\section{Political Correlates}

Political cognitive motivations. The survey instrument included a number of variables assessing individuals' motivation to cognitively engage with political issues. Two measures utilizing a five-point scale ( 1 = "not at all interested"; 5 = "very interested") asked, "In general, how interested are you in politics?" $(\mathrm{M}=3.70, \mathrm{SD}=1.01)$ and "How interested were you in the 2016 U.S. presidential election?” $(\mathrm{M}=4.44, \mathrm{SD}=.97)$. Respondents also indicated their level of agreement or disagreement with three seven-point Likert statements that reflected respondents' 
epistemic motivation to process political information ( 1 = "strongly disagree"; 7 = "strongly agree"): "The more viewpoints I get an issue, the better"; "It is quite important to me to know as much as possible about political issues"; and "It is important to me to know all argument of political discussions in detail" $(\mathrm{M}=5.52 ; \mathrm{SD}=1.16$; Cronbach's alpha $=.79)$.

Political information processing. The political information processing behavior of respondents' was gauged using two measures. The first consisted of four seven-point Likert statements related to elaborative processing ( 1 = "strongly disagree"; 7 = "strongly agree"): "I rarely spend much time thinking about political news" (reverse-coded); "I often skim through news stories on political issues" (reverse-coded); "I tune in to news about political issues very irregularly" (reverse-coded); and "I am not that interested in details. It is sufficient to get the general idea of political issues" (reverse-coded) $(\mathrm{M}=4.26$; $\mathrm{SD}=1.28$; Cronbach's alpha $=.72)$. Respondents also were asked to indicate using an 11-point scale ( $0=$ "no attention at all"; $10=$ "a great deal of attention") how much attention they generally paid to national news and politics, news about the 2016 election, news about immigration policy, and news about international affairs. The four items were averaged to create a scale of political news attention ( $\mathrm{M}=7.32, \mathrm{SD}$ $=2.30$; Cronbach's alpha $=.92$ ).

Factual political knowledge. The survey instrument also included measures related to two types of political knowledge. Respondents were presented a series of multiple-choice questions that dealt with: the political party that controlled Congress; the Supreme Court Justice who died earlier in the year; and the country whose residents voted earlier in the year to leave the European Union. Correct responses were summed to create a single scale of general political knowledge $(\mathrm{M}=2.12, \mathrm{SD}=.93 ;$ Cronbach's alpha $=.48)$.

The second type of political knowledge concerned knowledge about the 2016 campaign, an index comprising eight true-false items: whether Hillary Clinton supported extending the 
Affordable Care Act health plans regardless of a person's immigration status; whether WikiLeaks released transcripts on the Internet of Hillary Clinton's hacked emails and of her speeches to Wall Street firms; whether in the presidential primaries, President-elect Donald J. Trump had Jorge Ramos of Univision evicted from a press conference in Iowa; that Pope Francis endorsed Donald J. Trump for president; whether an FBI agent investigating Hillary Clinton's use of a private email server was found dead in an apparent murder-suicide; whether Hillary Clinton was serving as a U.S. Senator from the state of New York during the terrorist attacks of September 11, 2001; whether Trump has referred to global warming, or climate change, as "a total hoax"; and whether Trump has proposed building an impenetrable physical wall on the U.S. Southern border that he says Mexico will pay for $(\mathrm{M}=6.52, \mathrm{SD}=1.26$; Cronbach's alpha $=.31)$.

Political attitudes. To the extent that listening styles may be related to specific political attitudes, our analyses include additional items and indices. The normative value of political disagreement was an averaged index of three standard Likert items that asked respondents whether: it is the job of citizens to overcome their own biases in consuming political content; it is important to hear others' ideas even if they are different from one's own; and political disagreement is an important part of American democracy $(\mathrm{M}=3.82, \mathrm{SD}=.91$; Cronbach's alpha $=.73)$.

Respondents were asked to indicate their levels of political trust on a five-point scale $(1=$ "do not trust at all"; 2 = "trust a little"; 3 = "trust somewhat"; 4 = "trust very much"; 5 = "trust completely") vis-à-vis local elected officials $(\mathrm{M}=2.62, \mathrm{SD}=.98)$ and democratic institutions $(\mathrm{M}=2.79, \mathrm{SD}=0.83$; Cronbach's alpha $=.79)$. The latter consisted of four items related to labor unions, Latin civic organizations (e.g., the National Council of La Raza; League of United Latin American Citizens (LULAC)), the national news media, and local news media. 
Also related to political attitudes is an index measuring one's social dominance orientation (Pratto, Sidanius, Stallworth \& Malle, 1994), which involves seeing oneself (or wanting to see oneself) as part of the dominant "in-power" group in society and therefore believing that inequality in society is acceptable. Sixteen items were included that asked respondents to rate the degree to which they felt negatively or positively toward each statement (1 = "very negatively"; 7 = "very positively"). Example items included: "Some groups of people are simply inferior to other groups"; "It's OK if some groups have more of a chance in life than others; "Group equality should be our ideal" (reverse-coded); and "We would have fewer problems if we treated people more equally" (reverse-coded). The items were averaged to create a scale of social dominance orientation (Cronbach's alpha $=.91)$.

Political participation. The survey instrument also included several dichotomous items that tapped into respondents' engagement with acts of collective political participation during the 2016 election cycle: attending a political rally; participating in a protest, march, or demonstration; attending a public hearing, town-hall meeting, or city-council meeting; and volunteering for a political candidate (Cronbach's alpha $=.53$ ). As well, respondents were asked about individual, solitary acts of political participation during the 2016 election cycle: writing or emailing a politician; making a campaign contribution; posting or wearing a political sign, banner, button, or bumper sticker; contacting a news organization; forwarding or "liking" a politician's message; subscribing to a political candidate's social media feed or blog; talking to others about politics; and trying to persuade others to vote a certain way (Cronbach's alpha = $.59)$.

In line with prior research (e.g., Bodie et al., 2013, p. 76), the four listening style dimensions are not fully orthogonal (see Appendix A). We therefore estimated the partial correlations of each individual listening style dimension with political outcomes, statistically 
controlling for the remaining dimensions as well as demographic variables that may causally precede both listening styles and political outcomes. These controls should lead to less biased estimates of the independent associations of each individual listening style dimension with the political outcomes of interest (for the methodological reasoning behind this approach to statistical control, see Sieberer, 2007).

\section{Results}

Table 1 displays the partial correlations of apophatic and cataphatic listening styles as conceptualized above and the five categories of political outcomes, controlling for demographics that may be causally related to both general listening dispositions and the studied outcomes (age, gender, education, and length of residence in the United States).

[Table 1 about here]

\section{Political Cognitive Motivations}

We first explored possible associations between individuals' interpersonal listening styles and generalized motivation to cognitively engage with political issues. The partial correlations in Table 1 show that analytical and critical listening styles were positively related to both general interest in politics and interest in the 2016 presidential election $(.10 \leq r \leq .12, p \leq .01)$. Task-oriented listening, in contrast, was negatively related to general interest in politics, $r=-.14$, $p<.001$. Relational $(r=.10, p=.007)$ but especially analytical $(r=.29, p<.001)$ and critical listening $(r=.18, p<.001)$ were positively related to participants' epistemic motivation to obtain a broad range of political information to form their opinions.

\section{Political Information Processing}

Are listening styles associated with the information-processing strategies that individuals use in their engagement with political issues and events, specifically the degree to which they favor elaborative processing of political information and the degree of attention paid to political 
news? We find that both a relational $(r=-.14, p<.001)$ and a task-oriented listening style $(r=$ $-.28, p<.001)$ are associated with less elaborative processing of political news, while a critical listening style is associated with greater elaboration $(r=.14, p<.001)$. Task-oriented listening is also associated with generally less self-reported attention to political news $(r=-.13, p=.001)$, while analytical $(r=.19, p<.001)$ and critical listening styles $(r=.18, p<.001)$ are related to more such attention paid.

\section{Factual Political Knowledge}

Third, we examined how different listening styles were related to citizens' political cognitions, specifically their ability to answer correctly two sets of questions related to facts about the 2016 U.S. election campaign and political issues in general. Relational listening was related to less general political knowledge $(r=-.11, p=.004)$, and a critical listening to greater knowledge about the 2016 election campaign $(r=.11, p=.004)$. Beyond these two, no relevant $(r \geq .10)$ correlations of listening styles with political knowledge were present in the data.

\section{Political Attitudes}

Our fourth set of partial correlations shed light on how listening styles are associated with four political attitudes. Analytical $(r=.20, p<.001)$ and critical listening styles $(r=.16, p<$ .001), but not relational and task-oriented listening, were positively related to placing greater positive value on political disagreement as an important part of democratic politics. While trust in elected officials was not related to any of the four listening style dimensions, those who reported a more relational listening style were more likely to trust information coming from democratic institutions $(r=.23, p<.001)$. Listening styles predicted participants' social dominance orientation (SDO, i.e., their general preference for group based hierarchy and inequality): Analytical $(r=-.12, p=.002)$ and critical listening styles $(r=-.14, p<.001)$ were 
associated with lower levels of SDO, while a more task-oriented listening approach was associated with higher $\operatorname{SDO}(r=.12, p=.001)$.

\section{Political Participation}

Finally, we asked whether and how listening styles are related to broad participatory aspects of citizens' political life. This final component of the analysis reveals that the ways in which citizens report listening to each other are not related to collective, socially oriented acts of political participation. However, self-reported critical listeners were more likely to engage in acts of individual, solitary political participation $(r=.16, p<.001)$, which was not related to relational, analytical, or task-oriented listening styles.

\section{Discussion}

Recognizing the importance of listening in democratic life, this study sheds empirical light on the democratic benefits of the different ways in which citizens can listen to each other -benefits that are more often asserted than tested, including in democratic theories like Dobson's (2014). Specifically, using established empirical listening theory, this study directly operationalizes a normative concept of listening, and employs it to explore the political correlates of interpersonal-listening practices in a national-level sample of survey respondents.

In a broad perspective, individual listening dispositions were most strongly associated with the political cognitive motivations of respondents and their habitual political information processing. Given that listening can be thought of, albeit reductively, as the interpersonal instantiation of receiving and processing information, this may not be surprising. But the four dimensions of individual listening studied were also associated with some more downstream aspects of political life, notably with citizens' levels of factual political knowledge and political attitudes, specifically with individuals' tendency to value political disagreement and their social 
dominance orientation. In addition, a relational listening style focused on understanding the emotions of others was associated with greater trust in democratic institutions.

When we look at the four examined dimensions of individual listening styles in comparison, several findings stand out. First, relational listening, which is expressive of a concern with and awareness of others' feelings and emotions and represents the social-moral dimension of apophatic listening, emerges as ambivalent. It was associated with a greater motivation of individuals to hear a broad array of viewpoints on political issues (epistemic motivation). More notably, however, it was the only listening style disposition that was associated with a considerably greater trust in democratic institutions. At the same time, it also was associated with a tendency to engage with political issues more superficially and with lower knowledge of general political facts. From a normative point of view, relational listening thus appears to be a double-edged sword: Relational listeners appear to be interested in including as many voices in their own political opinion formation as possible, but they are less interested in the instrumental, epistemic aspects of politics, which is reflected in their tendency to have greater trust in the institutions of representative democracy. Whether this latter tendency is desirable from a normative standpoint will likely depend on whether those same political institutions are actually deserving of such trust. Whether relational listeners are responsive to political circumstance and adapt their institutional trust accordingly is, of course, in need of further investigation.

Second, analytical listening, the cognitive-epistemic dimension of apophatic listening, which is characterized by an intention to "hear out" speakers prior to forming a judgment emerges as more unambiguously conducive to desirable political outcomes. Analytical listeners reported greater interest and epistemic motivation to engage in politics, and they paid more 
attention to political news, placed greater value on disagreement as a constituent part of democratic life, and expressed less support of antiegalitarian social attitudes (SDO).

Third, task-oriented listening, conceived here as the social-moral dimension of cataphatic listening and which describes a general concern with scarce time resources in conversations and a desire to interact efficiently, emerged as irrelevant to many and negatively related to some of the political outcomes studied. Task-oriented listeners appeared particularly prone to a more superficial cognitive engagement with politics, as they exhibited a lower general interest in politics, lower attention to political news as well as lower interest in drawing on a broad range of viewpoints and arguments in forming their political opinions. Finally, they showed greater support for group-based social hierarchy and dominance.

Fourth, a critical - or error-seeking - listening style, which was understood here as capturing the cognitive-epistemic dimension of unproductive cataphatic listening, surprisingly emerged from this empirical analysis as consistently favorable from a normative point of view. A disposition to listening critically, like a disposition to listen analytically, was associated with greater cognitive motivation to engage with and process political information. This was also the only listening style that was associated with somewhat greater factual knowledge (about the 2016 election campaign). Also similar to analytical listeners, critical listeners endorsed disagreement as part of democratic politics and were less likely to exhibit an orientation supporting social inequalities based on social group membership alone. Finally, critical listening was the only listening style dimension related to greater individual political participation. In sum, the potentially disruptive tendency of critical listeners to critically assess messages for accuracy and consistency is associated with positive cognitive, attitudinal, and behavioral political outcomes, a finding that appears opposed to the clear-cut dismissal of this listening practice by Dobson (2014) and others. Taken together, these findings provide us with a more differentiated, 
empirically grounded view of the democratic value of different ways of listening to others than was previously available in the literature.

It is important to remember, however, that the set of political correlates investigated here was predominantly cognitive in nature. The selection of "criteria" against which to evaluate different ways of listening may have been biased against the more social-morally oriented relational way of attending to others. Had we asked respondents, for example, about their tolerance of disagreeing others, their perceived legitimacy of political opposition, their empathy, their willingness to compromise, their social trust, or their sense of community, we may have found evidence of the beneficial nature of this relation-focused approach to listening.

Equally important, our multidimensional operationalization of interpersonal listening and the variable-centered analysis of our data indicate that, unlike previously assumed, the empirical evidence points to a need for more nuance in normatively assessing different forms of listening. In sum, the empirical story with regard to the democratic role that listening practices can play is more complex than has been suggested in normative theory. Most strikingly, unlike assumed by theorists like Dobson (2014), critical, error-seeking listening - a form of "monologic" listening may well stand in the way of a genuine understanding of others (something we cannot test with our data), but it also is associated with several desirable political outcomes.

While our study is the first to examine how listening styles relate to political outcomes, we must note that the menu of democratic outcomes is not exhaustive. As noted above, the outcomes investigated here focus on the cognitive, not social-moral, aspects of political life. For example, the constructs measured here are unable to tap directly citizens' recognition and understanding across line of political difference. The social-moral dimension of apophatic listening thus may have been underrepresented in this empirical analysis. Hence, our results should not be read as passing judgment on the democratic merits, or lack thereof, of relational 
listening. We can take away, however, that relative to analytical and critical listening approaches, a relational listening style is less strongly tied to normatively desirable cognitive political outcomes like general interest in political events and issues, or deep processing and learning of political information.

Also, while this study investigated listening styles, the items did not ask about the immediate political context within which citizens' listening dispositions are likely to carry the most weight: political conversation and discussion. Future studies should employ research designs that allow scholars to empirically test a key assumption implicit in normative democratic theory - namely, that the different ways in which citizens may listen to each other across lines of political difference lead to varying levels of mutual recognition, sense of shared civic identity, and affective polarization.

It is clear that both the received normative wisdom regarding the merits of apophatic and perils of cataphatic listening styles is in need of greater nuance. Indeed, that both apophatic analytical listening and cataphatic critical listening are associated with desirable political outcomes on the individual level reminds us that, as Chambers (2013) puts it, good citizenship has many faces. Based on the findings presented here, we may add indeed that it appears to also have many ears. 


\section{References}

Barber, J. D. (1973). Citizen politics (3rd ed.). Chicago, IL: Markham Publishing.

Bassel, L. (2017). The politics of listening: Possibilities and challenges for democratic life. London, England: Palgrave Pivot.

Berelson, B., Lazarsfeld, P. F., \& McPhee, W. (1954). Voting: A study of opinion formation in a presidential campaign. Chicago, IL: University of Chicago Press.

Bickford, S. (1996). The dissonance of democracy: Listening, conflict, and citizenship. Ithaca, NY: Cornell University Press.

Bodie, G. D., \& Worthington, D. L. (2017). Listening Styles Profile-Revised (LSP-R). In D. L. Worthington \& G. D. Bodie (Eds.), The sourcebook of listening research (pp. 402-409). Hoboken, NJ: Wiley. https://doi.org/10.1002/9781119102991.ch42

Bodie, G. D., Worthington, D. L., \& Gearhart, C. C. (2013). The Listening Styles Profile-Revised (LSP-R): A scale revision and evidence for validity. Communication Quarterly, 61(1), 72-90. https://doi.org/10.1080/01463373.2012.720343

Chambers, S. (2013). The many faces of good citizenship. Critical Review, 25(2), 199-209. https://doi.org/10.1080/08913811.2013.843874

Couldry, N. (2009). Rethinking the politics of voice. Continuum, 23(4), 579-582. https://doi.org/10.1080/10304310903026594

Dahl, R. A. (1989). Democracy and its critics. New Haven, CT: Yale University Press.

Delli Carpini, M. X. (2004). Mediating democratic engagement: The impact of communications on citizens' involvement in political and civic life. In L. L. Kincaid (Ed.), The handbook of political communication research (pp. 395-434). Mahwah, NJ: Lawrence Erlbaum Associates. 
Delli Carpini, M. X., \& Keeter, S. (1996). What Americans know about politics and why it matters. New Haven, CT: Yale University Press.

Dobson, A. (2012). Listening: The new democratic deficit. Political Studies, 60(4), 843-859. https://doi.org/10.1111/j.1467-9248.2012.00944.x

Dobson, A. (2014). Listening for democracy: Recognition, representation, reconciliation. Oxford, England: Oxford University Press.

Ercan, S. A., Hendriks, C. M., \& Dryzek, J. S. (in press). Public deliberation in an era of communicative plenty. Policy \& Politics. https://doi.org/10.1332/030557318X15200933925405

Eveland, W. P., Jr. (2001). The cognitive mediation model of learning from the news: Evidence from nonelection, off-year election, and presidential election contexts. Communication Research, 28(5), 571-601. https://doi.org/10.1177/009365001028005001

Harcup, T. (2015). Listening to the voiceless: The practices and ethics of alternative journalism. In C. Atton (Ed.), The Routledge companion to alternative and community media (pp. 313-323). Milton Park, England: Routledge.

Ivie, R. L., \& St. Onge, J. (2016). Political knowledge. In G. Mazzoleni (Ed.), The international encyclopedia of political communication. https://doi.org/10.1002/9781118541555.wbiepc112

McLeod, D. M., Kosicki, G. M., \& McLeod, D. M. (2002). Resurveying the boundaries of political communication effects. In J. Bryant \& D. Zillmann (Eds.), Media effects: advances in theory and research (pp. 215-267). Mahwah, NJ: Lawrence Erlbaum Associates.

Moy, P., \& Pfau, M. (2000). With malice toward all? The media and public confidence in democratic institutions. Westport, CT: Praeger. 
Nie, N. H., Junn, J., \& Stehlik-Barry, K. (1996). Education and democratic citizenship in America. Chicago, IL: University of Chicago Press.

Norris, P. (2003). Democratic phoenix: Reinventing political activism. Cambridge, MA: Harvard University Press.

Oser, J., Hooghe, M., \& Marien, S. (2013). Is online participation distinct from offline participation? A latent class analysis of participation types and their stratification. Political Research Quarterly, 66(1), 91-101. https://doi.org/10.1177/1065912912436695

Pratto, F., Sidanius, J., \& Levin, S. (2006). Social dominance theory and the dynamics of intergroup relations: Taking stock and looking forward. European Review of Social Psychology, 17, 271-320. https://doi.org/10.1080/10463280601055772

Pratto, F., Sidanius, J., Stallworth, L. M., \& Malle, B. F. (1994). Social dominance orientation: A personality variable predicting social and political attitudes. Journal of Personality and Social Psychology, 67(4), 741-763. https://doi.org/10.1037/0022-3514.67.4.741

Rubin, A. M. (2002). The uses-and-gratifications perspective of media effects. In J. Bryant \& D. Zillmann (Eds.), Media effects: Advances in theory and research (pp. 525-548). Mahwah, NJ: Lawrence Erlbaum Associates.

Scheufele, D. A. (2002). Examining differential gains from mass media and their implications for participatory behavior. Communication Research, 29(1), 46-65. https://doi.org/10.1177/009365020202900103

Schudson, M. (1998). The good citizen: A history of American civic life. New York, NY: Free Press.

Scudder, M. F. (2016). Beyond empathy: Strategies and ideals of democratic deliberation. Polity, 48(4), 524-550. https://doi.org/10.1057/s41279-016-0001-9 
Sieberer, U. (2007). Selecting independent variables: Competing recommendations for factor-centric and outcome-centric research designs. In T. Gschwend \& F. Schimmelfennig (Eds.), Research design in political science: How to practice what they preach (pp. 163-182). Basingstoke, UK: Palgrave Macmillan.

Thill, C. (2009). Courageous listening, responsibility for the other and the Northern Territory Intervention. Continuum, 23(4), 537-548. https://doi.org/10.1080/10304310903012651

van Deth, J. W. (2014). A conceptual map of political participation. Acta Politica, 49(3), 349-367. https://doi.org/10.1057/ap.2014.6

Waller, L., Dreher, T., \& McCallum, K. (2015). The listening key: Unlocking the democratic potential of indigenous participatory media. Media International Australia, 154(1), 57-66. https://doi.org/10.1177/1329878X1515400109

Watson, K. W., Barker, L. L., \& Weaver, J. B., III. (1995). The Listening Styles Profile (LSP-16): Development and validation of an instrument to assess four listening styles. International Journal of Listening, 9(1), 1-13. https://doi.org/10.1080/10904018.1995.10499138

Xenos, M., \& Moy, P. (2007). Direct and differential effects of the Internet on political and civic engagement. Journal of Communication, 57(4), 704-718. https://doi.org/10.1111/j.1460-2466.2007.00364.x

Zaller, J. (2003). A new standard of news quality: Burglar alarms for the monitorial citizen. Political Communication, 20(2), 109-130. https://doi.org/10.1080/10584600390211136 
Table 1: Partial Correlations of Listening Styles with Political Outcomes

\begin{tabular}{|c|c|c|c|c|}
\hline & \multicolumn{4}{|c|}{ Listening Style } \\
\hline & \multicolumn{2}{|c|}{ Apophatic Listening } & \multicolumn{2}{|c|}{ Cataphatic Listening } \\
\hline & Relational & Analytical & Task-oriented & Critical \\
\hline \multicolumn{5}{|l|}{ Political cognitive motivations } \\
\hline Interest in politics (general) & $.07(.060)$ & $.12(.001)$ & $-.14(.000)$ & $.12(.001)$ \\
\hline Interest in politics (2016 election) & $.05(.160)$ & $.10(.011)$ & $.06(.139)$ & $.12(.002)$ \\
\hline Epistemic motivation & $.10(.007)$ & $.29(.000)$ & $-.05(.177)$ & $.18(.000)$ \\
\hline \multicolumn{5}{|l|}{ Political information processing } \\
\hline Elaborative processing & $-.14(.000)$ & $.09(.013)$ & $-.28(.000)$ & $.14(.000)$ \\
\hline Political news attention & $.01(.795)$ & $.19(.000)$ & $-.13(.001)$ & $.18(.000)$ \\
\hline \multicolumn{5}{|l|}{ Factual political knowledge } \\
\hline General political knowledge & $-.11(.004)$ & $.06(.129)$ & $-.02(.595)$ & $.08(.042)$ \\
\hline 2016 campaign knowledge & $-.04(.272)$ & $.08(.036)$ & $-.05(.152)$ & $.11(.004)$ \\
\hline \multicolumn{5}{|l|}{ Political attitudes } \\
\hline $\begin{array}{l}\text { Normative value of political } \\
\text { disagreement }\end{array}$ & $-.09(.023)$ & $.20(.000)$ & $-.03(.415)$ & $.16(.000)$ \\
\hline Political trust in elected officials & $.05(.155)$ & $.04(.264)$ & $-.06(.096)$ & $-.03(.422)$ \\
\hline Political trust in democratic institutions & $.23(.000)$ & $.02(.672)$ & $-.03(.414)$ & $-.09(.015)$ \\
\hline Social dominance orientation & $-.02(.630)$ & $-.12(.002)$ & $.12(.001)$ & $-.14(.000)$ \\
\hline \multicolumn{5}{|l|}{ Political participation } \\
\hline $\begin{array}{l}\text { Collective (socially oriented) } \\
\text { participation }\end{array}$ & $.04(.284)$ & $.07(.069)$ & $-.04(.328)$ & $.05(.221)$ \\
\hline Individual (solitary) participation & $.04(.267)$ & $.03(.416)$ & $-.08(.035)$ & $.16(.000)$ \\
\hline$N_{\min }$ & 714 & 714 & 714 & 714 \\
\hline$N_{\max }$ & 715 & 715 & 715 & 715 \\
\hline
\end{tabular}

Note: Cell entries are partial correlation coefficients controlling for the three respective other listening style dimensions as well as age (in years), gender, length of residence in the US (in years), and education level, with $p$-values in parentheses. 


\section{Normative Conceptualization}

(Dobson, 2014)

apophatic listening

(suspended categories /

dialogic)

cataphatic listening

(imposed categories /

monologic)

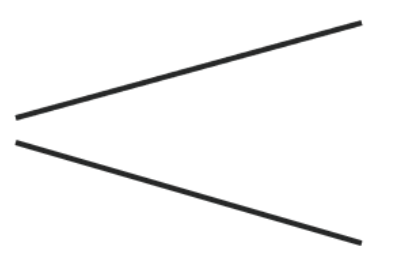

analytical listening

\section{Empirical Operationalization}

(Bodie et al., 2013)

relational listening

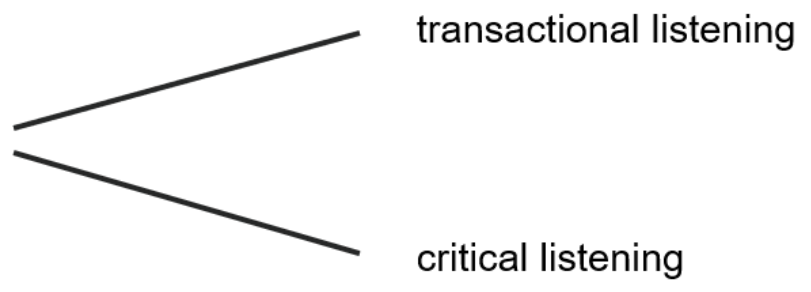

Figure 1. A normative conception of listening and the empirical dimensions of dispositional listening behavior 


\section{Appendix A}

\section{Zero-Order Correlations of Listening-Style Dimensions}

Table A1: Zero-Order Correlations among Listening-Style Dimensions

\begin{tabular}{|c|c|c|c|c|}
\hline & \multicolumn{4}{|c|}{ Listening Style } \\
\hline & \multicolumn{2}{|c|}{ Apophatic Listening } & \multicolumn{2}{|c|}{ Cataphatic Listening } \\
\hline & Relational & Analytical & $\begin{array}{l}\text { Task- } \\
\text { oriented }\end{array}$ & Critical \\
\hline \multicolumn{5}{|c|}{ Apophatic Listening } \\
\hline Relational & - & & & \\
\hline Analytical & $.44(.000)$ & - & & \\
\hline \multicolumn{5}{|c|}{ Cataphatic Listening } \\
\hline Task-oriented & $.00(.930)$ & $.00(.909)$ & - & \\
\hline Critical & $.26(.000)$ & $.27(.000)$ & $.20(.000)$ & - \\
\hline
\end{tabular}

Note: Cell entries are zero-order correlation coefficients, with $p$-values in parentheses. 